\title{
OS ANOS DE FORMAÇÃO DE ORLANDO RIBEIRO*
}

\author{
SUZANNE DAVEAU ${ }^{1}$
}

Em intróito às futuras conferências, destinadas a apresentar a um diversificado público algumas das múltiplas facetas da obra de Orlando Ribeiro, investigador, professor e cidadão esclarecido, vou comentar singelamente uma série de imagens fotográficas dos familiares e amigos que acompanharam a sua infância e os seus anos de formação. A parte principal da obra do professor e investigador não será aqui evocada, já que, a seguir, as conferências irão trazer luz sobre a sua actividade, bem mais variada que as habituais obrigações de uma carreira universitária.

Algumas das fotografias aqui reproduzidas foram já publicadas em 2003, nas Memórias de um Geógrafo, acompanhando os textos evocativos que Orlando Ribeiro elaborou e retocou várias vezes nos seus anos de maturidade e de velhice. Todas as citações não identificadas são extraídas deste conjunto de textos. Outras imagens fazem parte do Espólio Científico, que ele legou ao Centro de Estudos Geográficos de Lisboa, criado em 1943. A arrumação deste vasto conjunto documental está em vias de acabamento, sob a minha orientação, com a ajuda de vários membros da família e de profissionais, cuja competência e dedicação não podem deixar de ser aqui sublinhadas e agradecidas.

\section{ORIGENS FAMILIARES E INFÂNCIA}

Nascido em Lisboa em 16 de Fevereiro de 1911, Orlando Ribeiro teve uma infância não exclusivamente lisboeta. Sendo o pai e a mãe naturais de Viseu, ele sentiu-se sempre, ao mesmo tempo, filho da grande cidade portuária e descendente dos camponeses e serranos da Beira interior. Até podiam retomar-se as

* Texto de uma conferência integrada num ciclo em torno da obra de Orlando Ribeiro, que teve lugar na Biblioteca Orlando Ribeiro, a 24/4/04. Recebido: 08/10/2007. Revisto: 23/01/2008. Aceite: 14/02/2008.

1 Investigadora do Centro de Estudos Geográficos da Universidade de Lisboa.

E-mail: sdaveau@clix.pt 
palavras pelas quais Frei Bernardo de Brito opunha, em finais de quinhentos, "os portugueses da Beira, gente fera e indómita, alheia de todo trato político" e os "cidadãos de Lisboa (...) homens políticos e de bom governo". Talvez seja devido a esta dupla origem que provém o também duplo desejo de ser útil ao seu país, através do saber científico, aprofundado em plena liberdade, e de influenciar e melhorar, graças a este conhecimento renovado, a acção dos responsáveis do governo. Se ele recusou sempre, em absoluto, ser arrebanhado por qualquer partido político, sentiu certa amargura por ter sido tantas vezes afastado, a pretexto da sua incómoda falta de docilidade. Da sua dupla origem decorre também, talvez, tanto o interesse precoce pela Geografia das cidades como, mais ainda, pela diversificada vida do campo e pelas grandiosas paisagens a ela associadas. O campo foi de facto, durante a sua juventude, o palco dos tempos de livre vagabundagem durante as férias escolares e de afectuoso convívio com os avós maternos, deuses tutelares de um menino cedo órfão de mãe e criado, em Lisboa, por uma madrasta pouco amada.

Velhas fotografias permitem evocar as duas vertentes tão diferentes da sua infância. A primeira mostra um alegre almoço dominical, em companhia de familiares e amigos, numa tasca saloia dos arredores de Lisboa (fig. 1). O pequeno Orlando está sentado no primeiro plano à esquerda, o irmão Fernando, dois anos mais novo, ao fundo, ao colo da mãe, e o pai também ao fundo, à direita. Filho de um tipógrafo de Viseu, este foi, muito jovem, "fazer 13 anos ao balcão" de

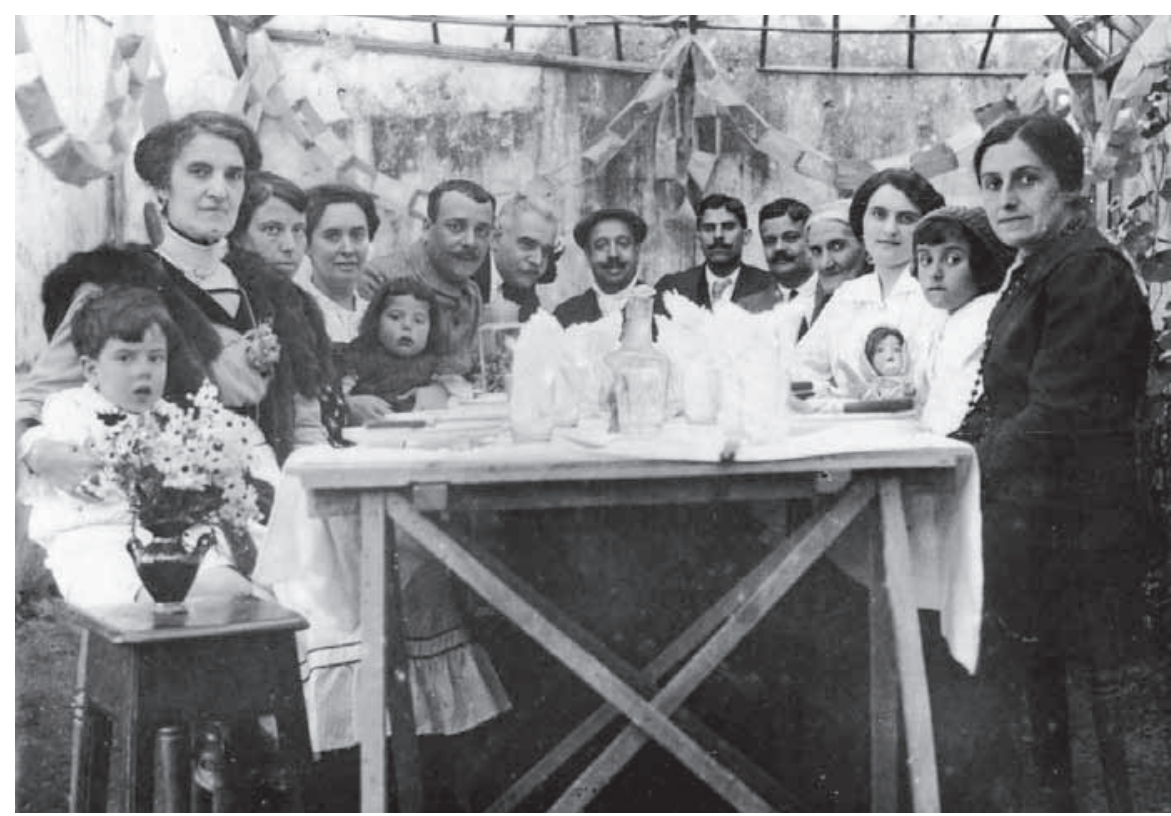

Fig. 1 - Almoço dominical na companhia de amigos, numa tasca do Pendão, em 1915. Fig. 1 - Sunday lunch in the suburbs of Lisbon, 1915. 
uma loja do Porto. Tendo casado em 1909 com uma prima, estabeleceu-se em Lisboa como gerente da Drogaria Progresso, sita na rua da Escola Politécnica, em frente da Faculdade de Ciências (fig. 2).

Este bairro lisboeta será o dos anos de escolaridade de Orlando. Primeiro, numa escola primária particular, onde conviveu com os filhos de Augusto Celestino da Costa, "grande figura da Ciência mundial" e vigoroso impulsionador da investigação científica em Portugal. Depois, no Liceu Passos Manuel, onde encontrou o grande amigo fraterno, Juvenal Esteves. Para mitigar as saudades do campo, apenas tinha à disposição tanto o vasto e exótico Jardim Botânico como o camaranchão da Praça do Príncipe Real, onde passava horas na biblioteca ao ar livre ali instalada.

Mas a doença e morte da mãe fizeram com que Orlando fosse em boa parte criado pelos avós. Lembrava-se sobretudo da vastidão do Asilo dos Inválidos Militares, em Runa, de que o avô foi um dos administradores durante a primeira guerra mundial. Mais tarde, passará as férias escolares em Viseu, perto dos avós ali retirados. A figura 3 mostra o jovem adolescente, no quintal da casa, frente ao galinheiro construído pelo avô. Augusto Carvela era um austero militar trasmontano, metódico e lido. Tendo assentado praça muito novo como voluntário, reformar-se-ia como major. A avó Amélia “aprendeu a ler mas apenas sabia desenhar o nome". Contava ao neto "histórias que encantavam a [sua] imaginação de criança" e "havia de iluminar, com a luz firme e clara do seu afecto, [toda a sua] vida interior".

Depois da morte do marido, a avó acabou os dias na tranquilidade da pequena aldeia do Curvel, ao pé da serra de Montejunto, numa família amiga, que reservou

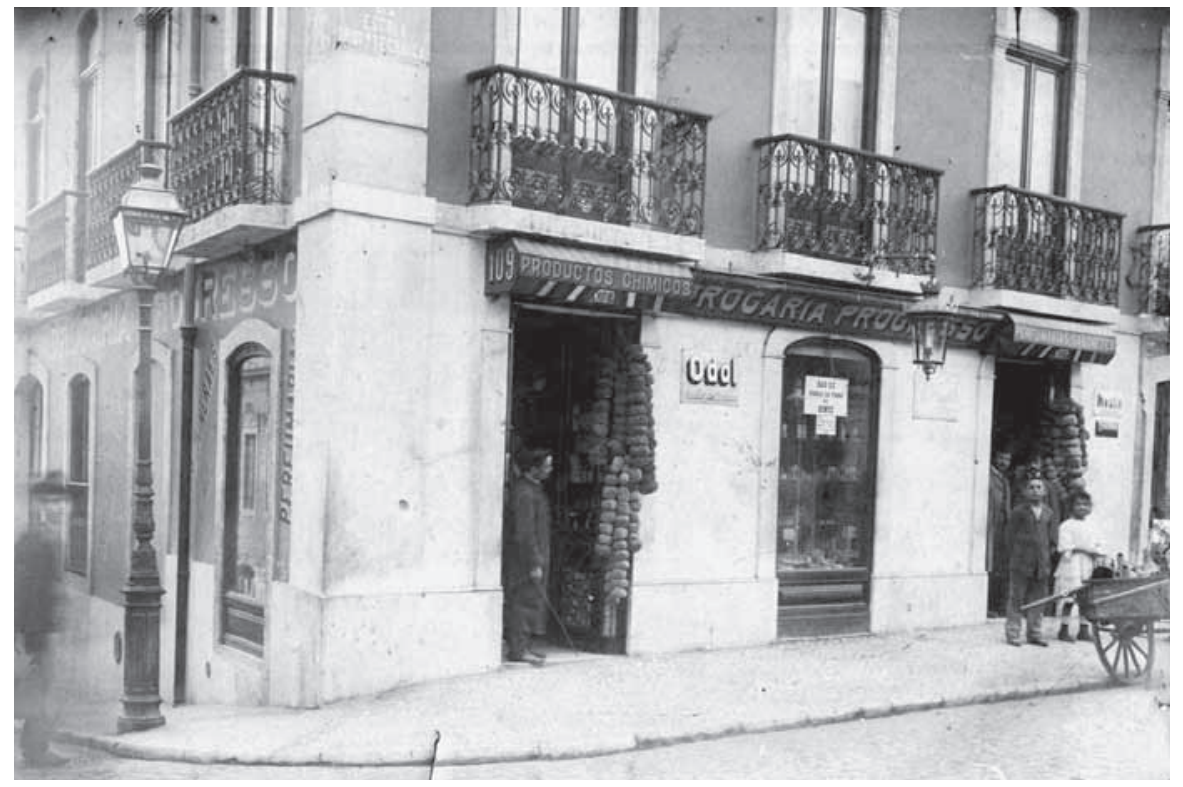

Fig. 2 - A Drogaria Progresso, na Rua da Escola Politécnica, Lisboa.

Fig. 2 - The Drugstore Progresso. 


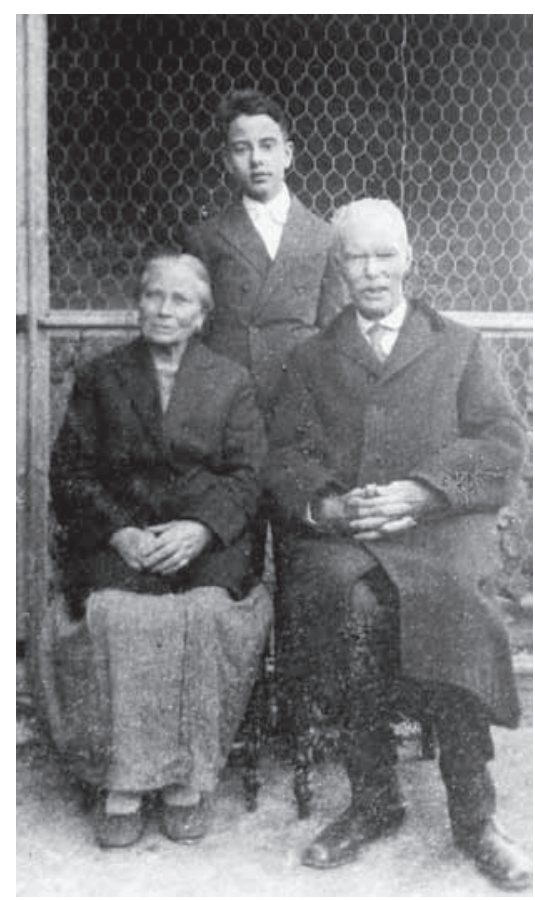

Fig. 3 - Na companhia dos avós maternos, durante as férias em Viseu.

Fig. 3 - Orlando Ribeiro with his grandparents, during holidays in Viseu.

um quarto para o "estudante", sempre presente durante as férias (fig. 4). Foi ali que, trepando com o irmão na encosta da serra, descobriu, chegado ao topo, a profunda depressão da Abadia, largamente aberta em margas dominadas por imponentes escarpas calcárias. Contará mais tarde que a sua paixão pela Geografia nasceu tanto ali, no campo, como na biblioteca de Viseu, onde descobriu e leu, durante outras férias, o Traité de Géographie Physique de Emmanuel de Martonne.

\section{OS ANOS DE FORMAÇÃO}

A chegada à Faculdade de Letras, em 1930, foi em boa parte uma desilusão. "Era, ao tempo, uma escola má com alguns professores excelentes (...). As aulas em certas cadeiras de Geografia eram de uma nulidade desoladora, em História de um impudor total, pois o professor ditava apontamentos traduzidos de livros que nos ocultava!". Mas Orlando Ribeiro soube, desde cedo, escolher quem seriam os seus verdadeiros mestres e teria o cuidado de lhes "pagar a dívida" mais tarde, evocando a sua vida e a sua obra. Dedicou-lhes, em particular, o Volume II dos seus Opúsculos Geográficos, o último que conseguiu preparar pessoalmente (Ribeiro, 1989), declarando: "Reuniram-se, neste volume, os estudos que consa- 


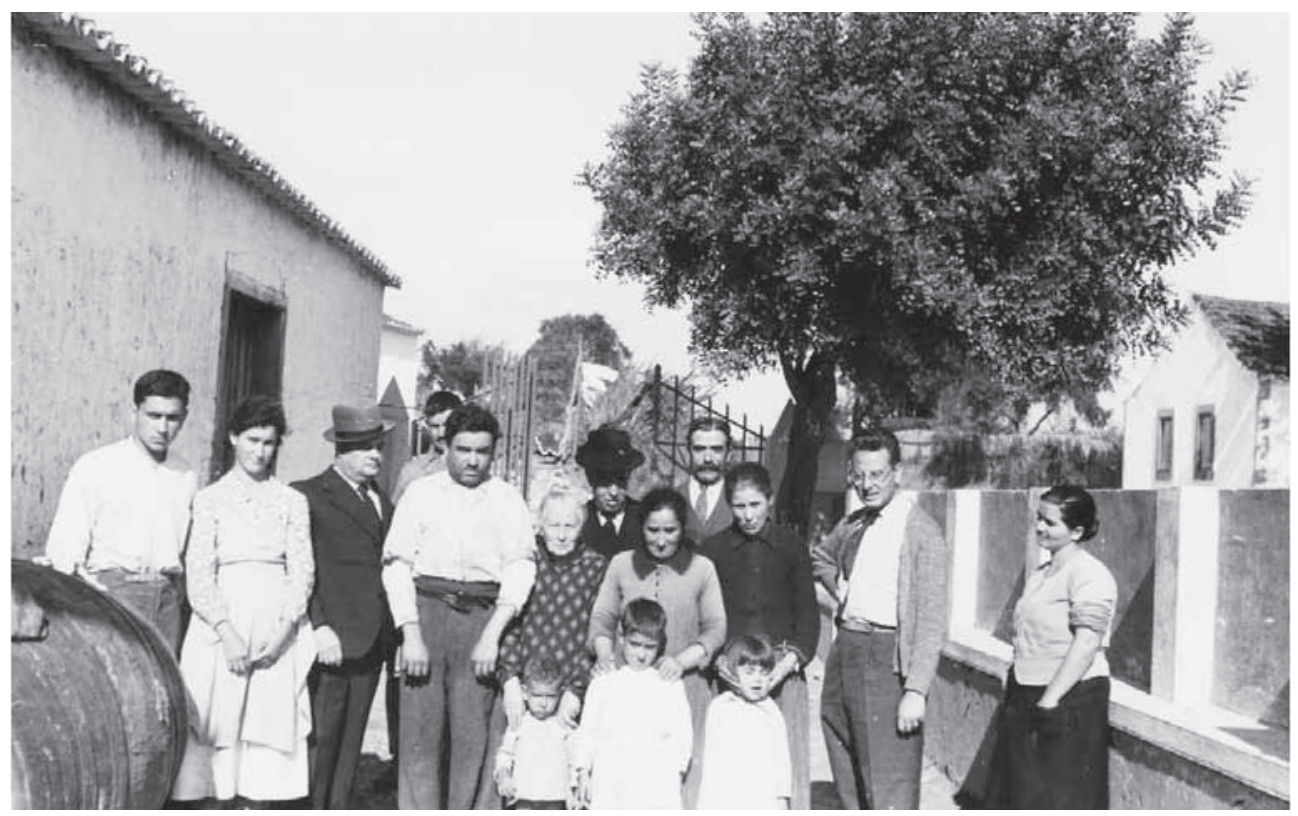

Fig. 4 - Na aldeia do Curvel, perto de Torres Vedras. Entre os membros de uma família saloia amiga, notam-se o pai, à esquerda, a avó, no meio, e o jovem geógrafo, à direita.

Fig. 4 - Orlando Ribeiro with family and friends in a village.

grei a geógrafos e outros pensadores que, de maneira ou outra, praticaram e enriqueceram a Ciência Geográfica. Uns são mestres que só conheci pela leitura atenta da obra, outros marcaram pessoalmente a minha aprendizagem e prática da Geografia, durante os anos de formação ou ao longo da vida, muitas vezes durante viagens de estudo (...). Outros ainda são colegas ou discípulos mais novos (...). Tive a sorte de conviver e tratar de perto com grandes figuras da Ciência".

Mas talvez não tenha sido apenas sorte. Verdade seja que ter sido criado num bairro "universitário" facilitou ao jovem estudante os primeiros contactos, mas bem poucos seriam, entre os colegas, os que tiveram coragem e paciência para servir de leitor a um professor cego, ou de amanuense a um velho sábio excêntrico.

Entre o corpo docente da Faculdade de Letras, sobressaía um único professor de Geografia, o médico Silva Telles, que "dava lindas aulas, mas onde nada se aprendia que pudesse aplicar-se à observação pessoal”. Ele ia morrer de repente, antes do fim do primeiro ano. Mais influência teve o professor de História, Manuel Ramos. "As aulas de propedêutica histórica mostravam-nos como se elaborava uma ciência (...). Manuel Ramos era cego: alunos de boa vontade iam-no buscar e levar a casa e liam-lhe ou escreviam o que ditava. Deste auxílio nos compensava generosamente, transmitindo-nos as reflexões que a leitura lhe sugeria (...). Levou-me a concertos pelo meu braço e muitas vezes o ouvi discretear com Viana da Mota, que o visitava com frequência.” A foto (fig. 5) mostra o professor em 1913, já cego, 


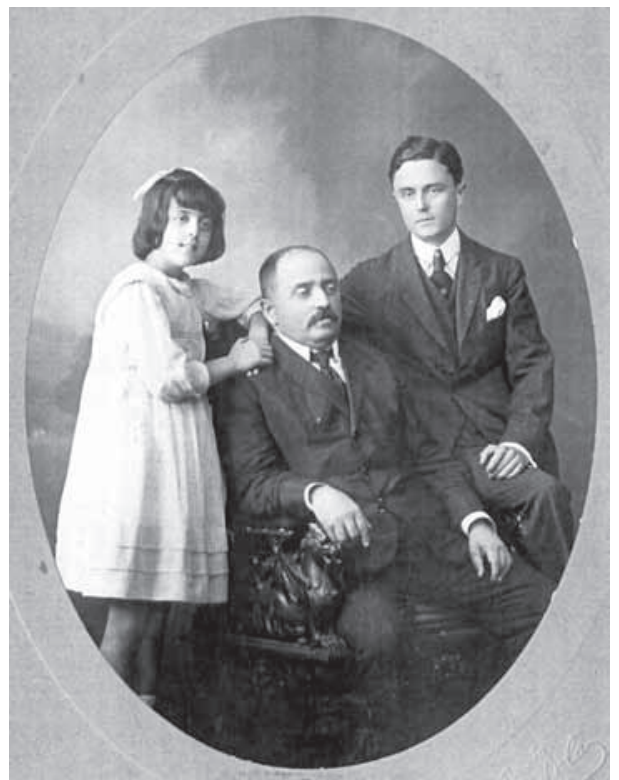

Fig. 5 - Manuel Ramos (1862-1931). Entre a filha Maria e o filho Manuel, em 1913.

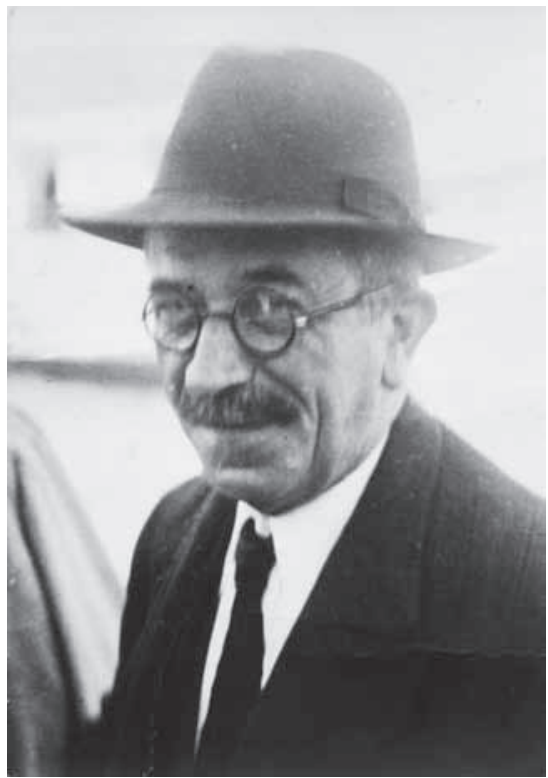

Fig. 6 - Ernest Fleury (1878-1958).

entre o filho Manuel e a filha Maria, com quem Orlando casaria em 1936, de tal modo que Manuel Ramos seria o "avô póstumo dos (seus) filhos".

Afinal, será fora da Faculdade que Orlando Ribeiro encontrará os verdadeiros mestres e inspiradores das suas futuras investigações. Ele fez-se discípulo voluntário do professor Ernest Fleury (fig. 6), um geólogo suíço que ensinava no Instituto Superior Técnico. Com ele, "uma tarde por semana, durante três ou quatro horas, exemplificava-se a Geologia numa longa excursão a pé. Pedreiras e barrancos eram cuidadosamente examinados (...), olhavam-se as formas, desenhando-se, a partir delas e da observação de direcções e pendores, cortes esquemáticos e interpretativos" (Ribeiro, 1970: 241-250). Destes exercícios, testemunha ainda o mais antigo dos 63 cadernos de campo que recolhem a enorme soma de observações acumulada por Orlando Ribeiro ao longo da vida. "A este excelente professor devo tudo o que (...) me foi possível aprender em Portugal no domínio da observação de campo."

Mais importante ainda, foi o convívio de Orlando Ribeiro com José Leite de Vasconcellos. "Estava já aposentado quando comecei a frequentar a sua casa [em 1931]. Era uma oficina de erudição (...). A ele, mais do que a ninguém, devo a posse de uma disciplina de trabalho e de um ideal de servir a Ciência." Já muito velho, Leite de Vasconcellos obrigava-se, à tarde, a trabalhar de pé, para não sucumbir ao sono (fig. 7). Escrevia no alto púlpito que tinha mandado instalar, de propósito, na sala onde acumulava a sua enorme documentação. Quando se encontrava fora de Lisboa, Orlando Ribeiro dava-lhe regularmente 


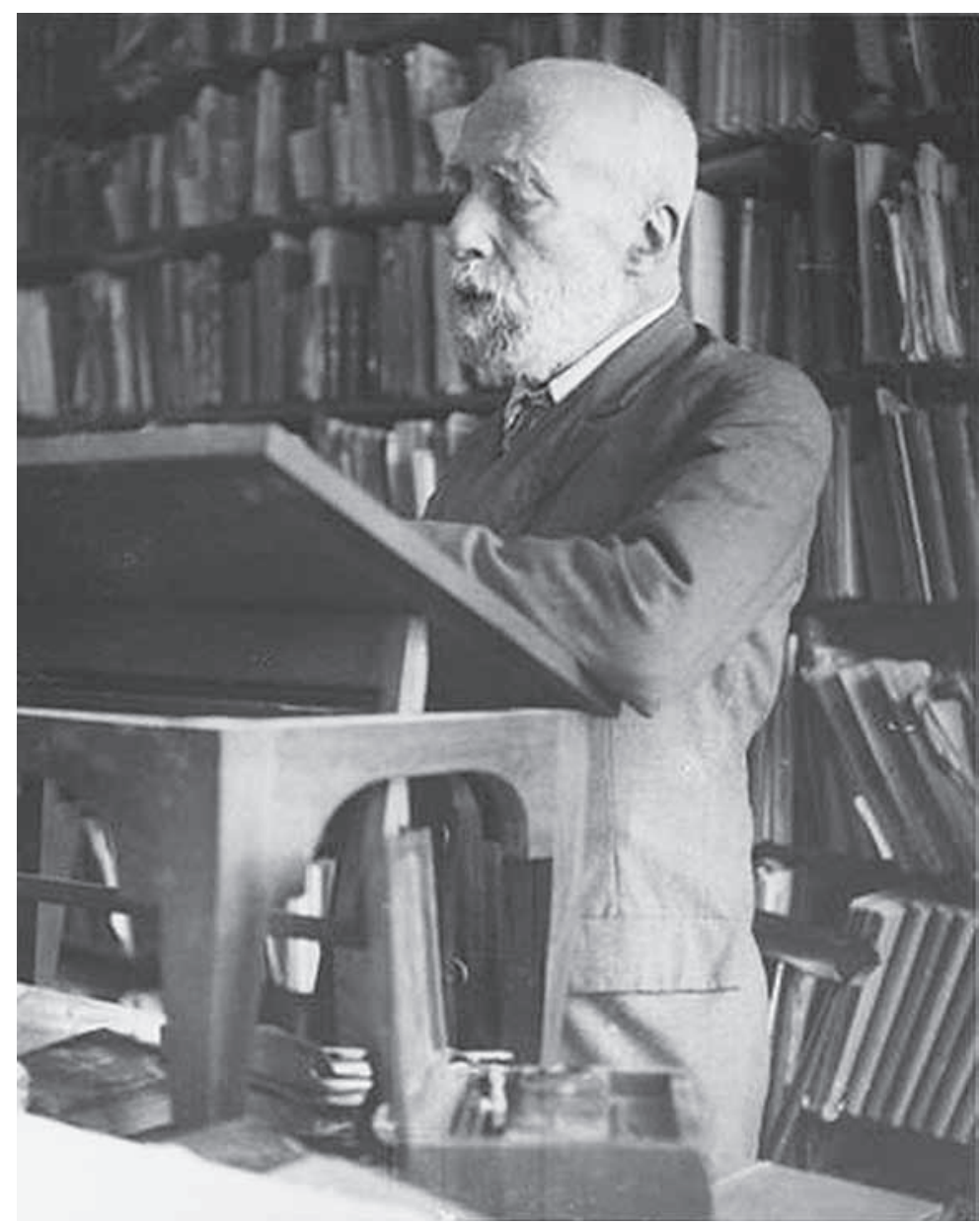

Fig. 7 - Leite de Vasconcellos (1858-1941). Escrevendo, de pé, na sua sala de trabalho.

conta das suas actividades, através de curtos e afectuosos bilhetes, felizmente hoje catalogados no Epistolário arquivado no Museu Nacional de Arqueologia (1999: 225).

Durante "os anos de Paris", de 1937 a 1940, Orlando Ribeiro manteve estreito convívio com dois grandes geógrafos franceses, Emmanuel de Martonne e Albert Demangeon. Eles tinham partilhado entre si a direcção científica do famigerado Institut de Géographie de la rue Saint Jacques, então o mais activo centro mundial de investigação em Geografia. Ali, o jovem português conheceu também condiscípulos das mais variadas nacionalidades e estabeleceu amizades duradouras, que serão as bases da sua larga rede de relações científicas internacionais. 
A Emmanuel de Martonne (fig. 8), ele dedicará mais tarde uma sentida e ampla homenagem na revista Finisterra (Ribeiro, 1973). Se "os nossos primeiros contactos não foram auspiciosos", em breve e sobretudo graças ao ensino prático recebido de Fleury, Orlando Ribeiro soube mostrar que tinha uma formação mais sólida "que outros portugueses que por aí tinham passado antes de mim." Foi então decidido que o discípulo português prepararia uma thèse d'État sobre a Beira Baixa, escolhida em razão da própria complexidade desta pequena "região de transição que, ao mesmo tempo recorda Trás-os-Montes e anuncia o Alentejo". Julgaram que seria o "caminho mais formativo para quem estaria talvez destinado a introduzir na sua terra os métodos da Geografia moderna". Mas "a guerra interrompeu brutalmente este estimulante convívio internacional." Em 1944, conseguindo escapar durante umas semanas à ocupação nazi, de Martonne veio descobrir Portugal em companhia do discípulo. Será também ele que, em 1946, reanimará o velho projecto da realização em Lisboa do primeiro Congresso Internacional de Geografia do pós-guerra. Decisão que era o manifesto sinal do grande apreço que o então Presidente da União Geográfica International tinha por um jovem geógrafo, ainda tão ignorado no seu próprio país.

Albert Demangeon (fig. 9), o outro mestre, "geógrafo completo e de grande envergadura, professor dotado de invulgar senso didáctico", morreu em Julho de 1940, isolado numa capital de repente abandonada pelos seus habitantes, que fugiam das tropas invasoras. E será o amigo Jean Gottmann, refugiado em Montpellier, que anunciará a Orlando Ribeiro a morte do mestre, a quem dizia dever tudo o que sabia de Geografia (Daveau, 2007 a). Em 24 de Outubro, Gottmann mandará a Orlando uma biografia detalhada de Demangeon e publicará, no ano seguinte, um denso artigo de homenagem, em parceria com Pierre Gourou (Gottmann, Gourou, 1941). Mas idêntica homenagem ficará entre os projectos não realizados por Orlando Ribeiro, ainda que nunca esquecido. Ouvi-lhe bastantes vezes evocar com gosto as longas conversas que tinha tido com Demangeon, ao descer a rue Saint Jacques depois das aulas, à hora do almoço.

Em complemento da séria e ampla formação recebida em Paris, não apenas de geógrafos mas também de geólogos como Bourcart e Jacob, ou de sociólogos como André Siegfried, Orlando Ribeiro teve o privilégio de conviver episodicamente, durante os seus anos de formação, com um grande geógrafo alemão. Conheceu-o primeiro no Congresso de Amesterdão, em 1938, quando Hermann Lautensach expôs a sua famosa teoria da Geografia regional (Lautensach, 1938) mas, mais ainda em 1943, quando ele conseguiu vir até Portugal, onde "percorremos juntos horst e graben de Trás-os-Montes, de Bragança até ao Douro, e toda a Cordilheira Central portuguesa (...). Raras vezes tive tão entusiástico companheiro de longos dias de jornada e nunca tão instrutivo (...). A minha formação francesa de jovem geógrafo recebeu assim o precioso complemento de uma informação germânica filtrada pelo grande poder de síntese e de crítica do meu ilustre interlocutor (...). É-me grato recordar (...) quanto devo aos seus trabalhos e à sua personalidade" (Ribeiro, 1971). Foi então que nasceu o projecto de uma Geografia de Portugal escrita em comum, projecto várias vezes protelado 
e que acabei por realizar, numa forma ao mesmo tempo inacabada e actualizada, em 1987-1991 (Daveau, In Ribeiro et al., 1987; Daveau, 2007 b).

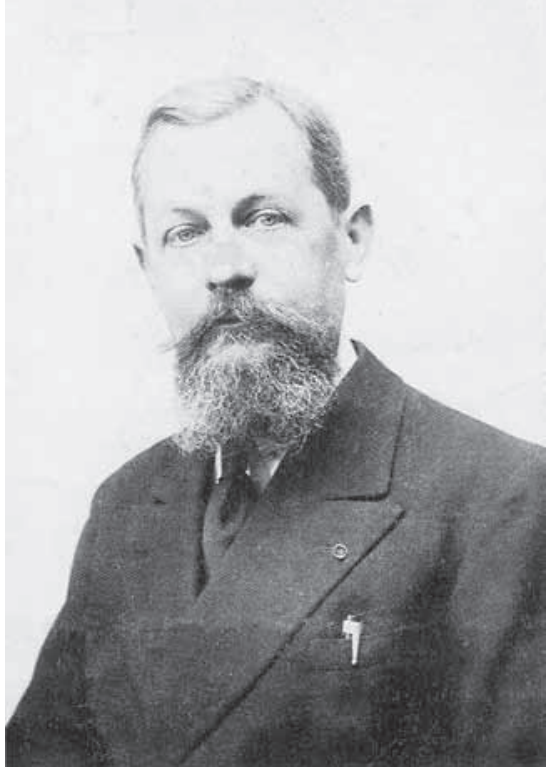

Fig. 8 - Emmanuel de Martonne (1873-1955).

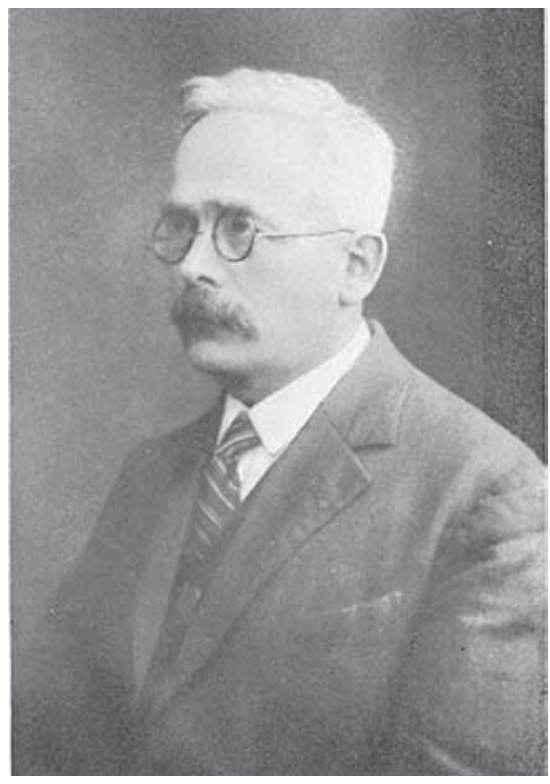

Fig. 9 - Albert Demangeon (1872-1940).

Em 1949, os geógrafos alemães tinham sido, em princípio, excluídos do primeiro Congresso Internacional do pós-guerra pelos Estados vencedores, por razões evidentemente bem pouco científicas. Mas Orlando Ribeiro, com o seu habitual desprezo pelas conveniências diplomáticas e a sua rara frontalidade, conseguiu que o autor da única Geografia de Portugal de nível universitário fosse, a título excepcional, convidado por Portugal a participar tanto no Congresso como na excursão à Madeira que se lhe seguiu. "Em Abril de 1949, durante duas semanas, reuniu-se na Madeira um conjunto, talvez único, de grandes figuras da Ciência, pertencentes a sete países" (Ribeiro, 1985) A figura 10 mostra o geógrafo alemão, no regresso da excursão, despedindo-se amigavelmente dos colegas portugueses na estação de Santa Apolónia.

Não menos importantes foram as ligações que Orlando Ribeiro estabeleceu muito cedo, mal acabada a Guerra Civil, com os geógrafos e geólogos espanhóis. Participou com eles em diversos cursos e excursões, através da Península Ibérica e do Norte de Marrocos. Não é também por acaso que a primeira versão da sempre almejada Geografia de Portugal orlandeana será publicada em castelhano e por uma casa editorial de Barcelona (Ribeiro, 1955; Daveau, 2007). Quanto à dedicatória (fig. 11) que Don Eduardo, o patriarca da família Hernández-Pacheco, escreveu no rosto da sua grande Fisiografia del Solar Hispano (1955), ela pode testemunhar as 


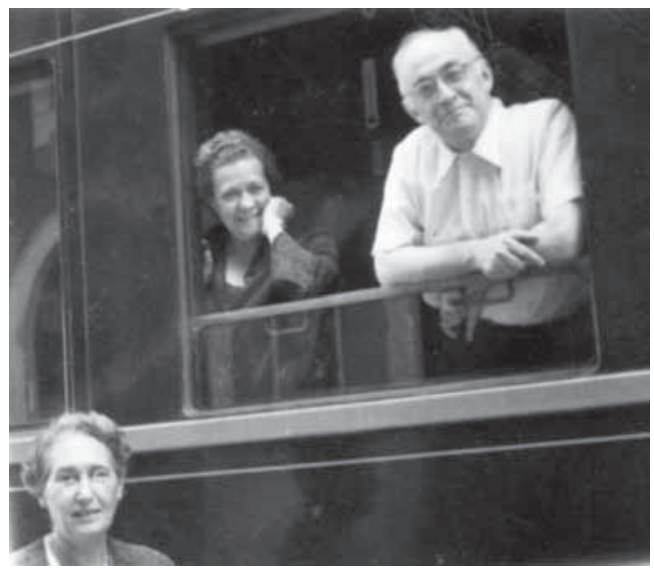

Fig. 10 - Hermann Lautensach despedindo-se dos colegas portugueses na estação de Santa Apolónia, depois da excursão à Madeira, em 1949.

Fig. 10 - Hermann Lautensach leaving Portugal after the IGU conference in 1949.

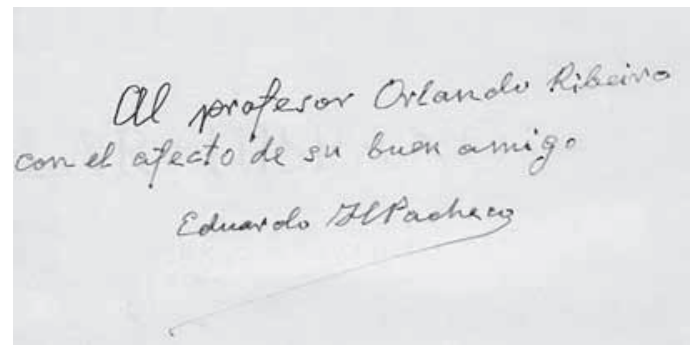

Fig. 11 - Dedicatória da Fisiografia del Solar Hispano (1955), por Eduardo Hernández-Pacheco.

Fig. 11 - "Fisiografia del Solar Hispano" dedicated to Orlando Ribeiro by Eduardo Hernández-Pacheco.

estreitas ligações afectivas e científicas então estabelecidas e que crescerão depois, cada vez mais amplas, entre geógrafos espanhóis e portugueses.

\section{OS COMEÇOS DA "ESCOLA GEOGRÁFICA DE LISBOA"}

Para uma plêiade de jovens investigadores portugueses, os anos de guerra foram um período de grande actividade. Recolhidos dos vários países europeus onde tinham recebido excelente e diversificada formação, passaram a "descobrir" os vários aspectos do próprio país, ainda tão pouco explorado. Não sem a ajuda de diversos colegas estrangeiros, refugiados em Portugal por motivos políticos ou... alimentares. Alegres companheiros de um intenso trabalho de campo foram tanto os geólogos Cotelo Neiva e Carlos Teixeira (fig. 12), Georges Zbyszewski 


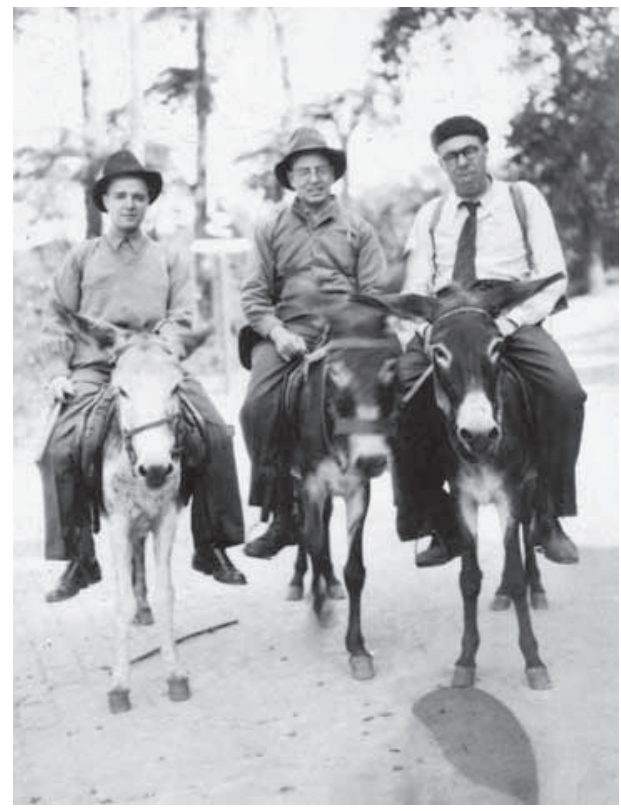

Fig. 12 - Orlando Ribeiro na companhia dos geólogos Cotelo Neiva e Carlos Teixeira, durante uma excursão.

Fig. 12 - Orlando Ribeiro during an excursion with the geologists Cotelo Neiva and Carlos Teixeira.

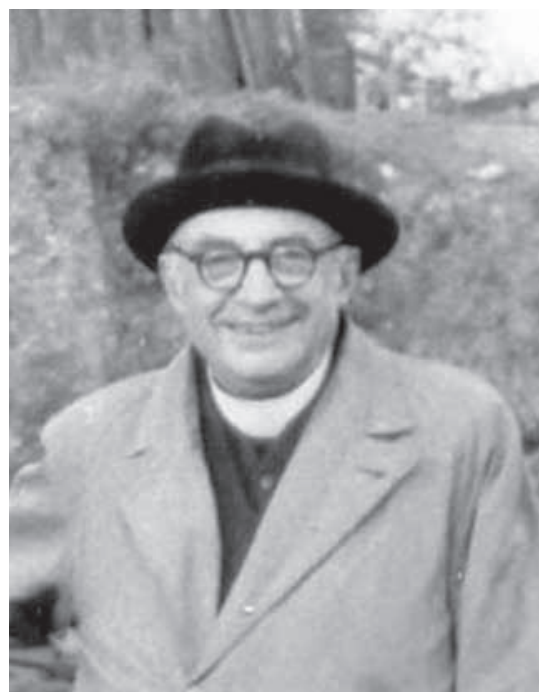

Fig. 13 - Henri Breuil (1877-1961). 


\section{MÉDITERRANÉE ET OCÉAN}

Chanterai-je le flirt de la mer océane,

La toujours vierge allumeuse,

Avec un vieux continent qui se fane

Sous l'haleine de l'enjôleuse?

Elle vient mordiller parfois un cou doré

Offrir tout son parfum et ses cheveux mêlés,

Puis se dérobe, et nargue sans les craindre

Les bras maigres des caps allongés pour l'étreindre.

En vain, et la lente succion du jusant,

Dans un lasso de vertiges, entraîne

Le trop naïf amoureux des sirènes

Vers un no man's land de sables mouvants

Où l'eau se mêle au ciel celtique

Dans un brouillard métaphysique,

Et sa rumeur nous vient comme d'une autre rive...

Parfois passe, en grondant, une île à la dérive,

Épave d'un monde englouti

Dont le pilote, pétrifié,

À grands bras, s'obstine à lancer

Des signes de croix sur la nuit.

Je chanterai plutôt les noces éternelles

D’Amphitrite et de Pélée

Méditerranée fidèle

Aux rocs qu'elle a épousés.

La lumière innombrable de ses yeux rieurs

Vient habiter la paix et des monts et des champs

Et ne dédaigne pas l'ombre d'un pin branlant.

Tous les chemins pierreux, tous les chemins brûlants

Descendent vers sa douceur.
Insinuée en calanques où bat un tambour

Plus secrète au fond des grottes,

Écoute la mer qui chuchote

La mer, heureuse en sa prison d'amour.

Pour rejoindre la bien aimée,

Broyant sa propre chair pétrée

De quel élan la montagne se cabre!

Dos d'herbe jaune et poitrine de marbre

À grand bruit, éclaboussant les flots.

Et le sang du soleil rejaillit jusqu'au faîte,

Le plus pur des autels pour la nocturne fête,

Le plus pur des tremplins pour le saut de Sapho.

Îles, joyeux enfants d'une union féconde,

Tous pétris d'un limon à la terre arrachée

Et longuement couvé au sein des ondes,

De coquilles encore parées, vous bondissez,

Mais, déjà poudrées d'oliviers,

Vous portez l'humaine livrée.

O mer toujours recommencée

Dont les entrailles frémissantes,

Sans jamais se lasser, enfantent

Les mêmes rocs, toujours nouveaux.

Et ta fuite la plus lointaine

Est encore sous l'atteinte humaine,

Ferme support du firmament,

Dont l'irréprochable coupure

Taille un ciel à notre mesure.

Poema inédito de Pierre Birot, datado de 1944, na Figueira da Foz. Resulta do concurso amigável e informal, aberto para celebrar a publicação de Portugal, o Mediterrâneo e o Atlântico.

Com apurado critério, será escolhido o poema de Miguel Torga, mas o pastiche de Pierre Birot tinha muito à-propos e graça e bem merece não ser esquecido.

O mais abruti dos geomorfólogos era, na realidade, um homem culto, generoso e cheio de fantasia. 


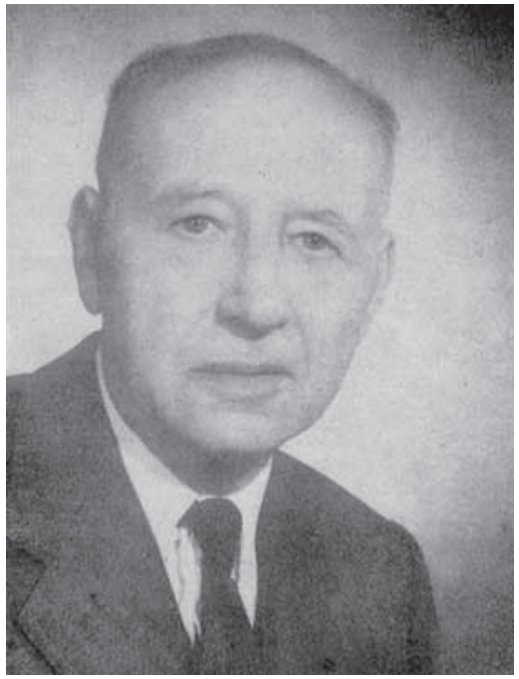

Fig. 14 - Pierre Birot (1909-1984).

e Décio Thadeu, como o velho arqueólogo Abbé Breuil (fig. 13) o geomorfólogo Pierre Birot (fig 14), o etnólogo Jorge Dias ou o filólogo Paiva Boleo.

Foi então, em Coimbra, na paz de um pequeno gabinete anexo à grande Biblioteca setecentista, que Orlando Ribeiro escreveu Portugal, o Mediterrâneo e o Atlântico (Ribeiro, 1945). O curioso pastiche telúrico, aqui reproduzido, que Pierre Birot lhe ofereceu nesta ocasião, testemunha do ambiente amigável e fervoroso, que reinava então entre os jovens investigadores.

Mas os alunos de Geografia continuavam a ser muito pouco numerosos. Quando começou a preparar o Congresso Internacional de Geografia de 1949, Orlando Ribeiro teve de pedir ajuda a um geólogo, a uma historiadora e a um etnólogo, para a direcção de metade das excursões previstas. Por sorte, tinha recentemente aparecido no "Centro" um lavrador-engenheiro, originário do Baixo Alentejo e formado em Paleontologia na Alemanha. Andando pelo campo na companhia de Amilcar Patrício, antigo aluno de Orlando Ribeiro na Universidade de Coimbra, Mariano Feio tinha tido a revelação do significado geomorfológico das acumulações de calhaus rolados, dominando o vigoroso entalhe do Guadiana. Entusiasmado com os métodos desta ciência de observação ao ar livre, Mariano Feio (fig. 15) tornou-se, em breve, para Orlando Ribeiro, um colaborador de alto nível, que "com o seu senso administrativo e o frio raciocínio, moderava alguns dos (seus) entusiasmos menos reflectivos", e foi dos seus amigos mais sólidos, autor "de uma obra científica que não tem paralelo entre nós".

Para assegurar as tarefas organizativas da grande reunião internacional, veio também propor-se um jovem sociólogo, originário de São Tomé e diplomado pela 


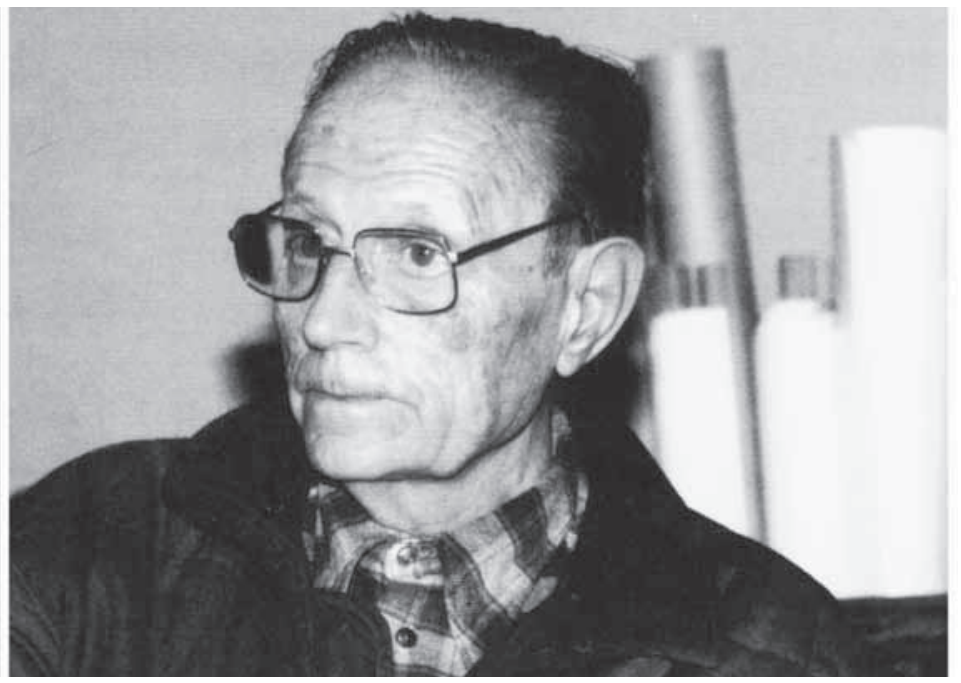

Fig. 15 - Mariano Feio

(1914-2001).

antiga Escola Superior Colonial (fig. 16). "Francisco Tenreiro veio para o Centro de Estudos Geográficos numa época de grande aperto de trabalho, como o meu secretário (...), veio e foi ficando, aproximando-se da Geografia pelo caminho das suas fundas curiosidades africanas e das suas predilecções sociológicas". Uma morte prematura, em 1963, ia infelizmente interromper a sua prometedora carreira.

Na mesma altura, Orlando Ribeiro recebeu também uma grande ajuda das primeiras alunas do curso de Geografia, sempre dispostas a desenhar mapas ou a escolher fotografias. Destacaram-se, entre elas, Maria Augusta Plácido Santos e, sobretudo, Raquel Soeiro de Brito (fig. 17). Esta infatigável companheira do trabalho de campo, mesmo em lugares exóticos e arriscados, foi também a paciente organizadora das primeiras colecções documentais que o jovem Centro de Estudos Geográficos começava a juntar. Entre os utilizadores actuais das suas ricas e prezadas Biblioteca, Mapoteca e Fototeca, quem saberá que boa parte das fichas foram pacientemente preenchidas por ela, durante anos? Tendo realizado depois investigações originais nas mais diversas partes do mundo, Açores, Brasil, Estados Unidos, África, Índia, Macau e Timor, ela criará e dirigirá com firmeza, na Universidade Nova de Lisboa, um Departamento de Geografia e Planeamento Regional.

Pouco a pouco, começaram a aparecer mais alunos de Geografia, nesta tradicionalmente desprezada disciplina, considerada "ciência auxiliar da História", que conseguirá apenas em 1957 atingir plena personalidade universitária. Mas, já em 1945, Orlando Ribeiro tinha publicado Portugal, o Mediterrâneo e o Atlântico, uma das obras básicas da cultura portuguesa. Nos anos 50, frequentaram o curso, primeiro Ilídio do Amaral, e alguns anos mais tarde Carminda Cavaco, Isabel Marques, António de Brum Ferreira, Jorge Gaspar, Carlos Alberto 


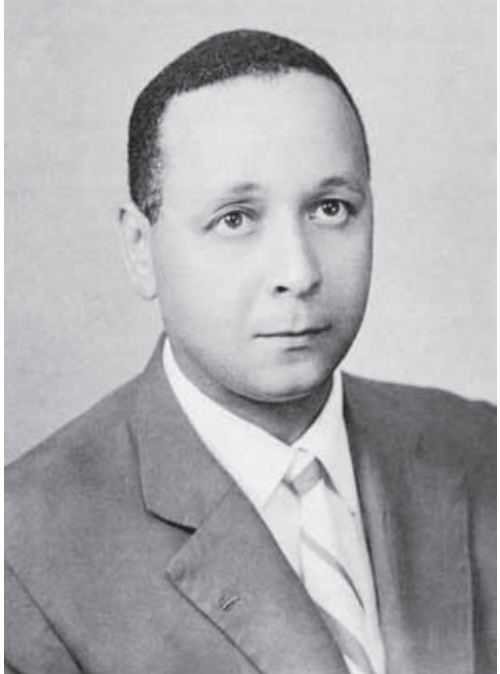

Fig. 16 - Francisco Tenreiro (1921-1963).

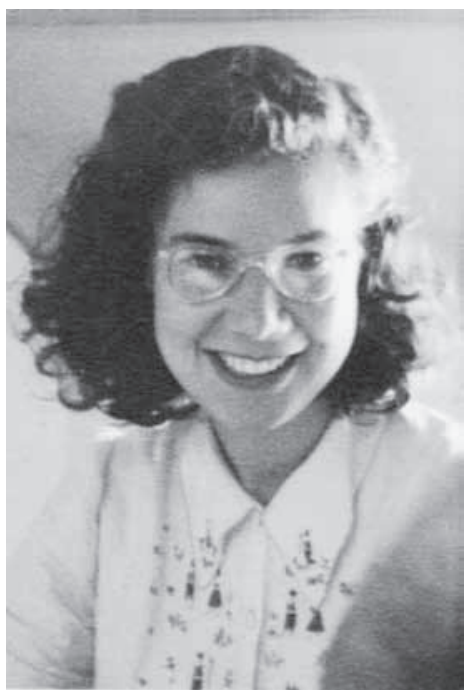

Fig. 17 - Raquel Soeiro de Brito.

Medeiros, entre muitos outros. Nomeado em 1952 Primeiro Vice-Presidente da União Geográfica Internacional, Orlando Ribeiro era definitivamente reconhecido como um mestre de estatura internacional. O que não significa que os meios de acção necessários a um desenvolvimento aprofundado e generalizado do conhecimento geográfico do país, lhe tenham sido atribuídos com um mínimo de continuidade. Os seus relatórios e memorandos, reunidos na segunda parte do presente número da revista Finisterra, exemplificam as múltiplas dificuldades contra as quais teve de lutar teimosamente, com maior ou com menor sucesso. Porque "se fui um homem livre", como escreverá ao aposentar-se em 1981, "também nunca tive audiência", por ser "considerado senão como um inimigo do governo, pelo menos como uma pessoa incómoda."

\section{OBRAS CITADAS}

Brito B (1597) Monarquia Lusitana. I, Alcobaça, (Livro 4, Cap. IX, p. 344 v e Cap. XIII, p. 356).

Daveau S (2007a) La Géographie, ça peut survivre à la guerre. Finisterra - Revista Portuguesa de Geografia, XLII (83): 5-20.

Daveau S (2007b) Planeamento e difusão das obras de Orlando Ribeiro In Geophilia - o Sentir e os Sentidos da Geografia, CEG, Lisboa: 171-183.

Daveau S (1987) Introdução e anexos III-VIII. In Ribeiro O, Lautensach H, Daveau S Geografia de Portugal. Edições João Sá da Costa, Lisboa, Vol. I: XI-XX: 290-297.

Epistolário de José Leite de Vasconcelos (1999) Suplemento n. ${ }^{\circ} 1$ de O Arqueólogo Português, Museu Nacional de Arqueologia, Lisboa: 225. 
Gottmann J, Gourou P (1941) Albert Demangeon (1872-1940). Bulletin de la Société Languedocienne de Géographie, 12: 1-15.

Hernández-Pacheco E (1955) Fisiografia del solar hispano. I, Real Academia de Ciencias Exactas, Fisicas y Naturales, Madrid.

Lautensach H (1938) Über die Erfassung und Abgrenzung von Landschaftsräumen. Comptes Rendus du Congrès International de Géographie, Amsterdam, II, Paysage Géographique: 12-26.

Ribeiro O (2003) Memórias de um geógrafo. Edições João Sá da Costa, Lisboa.

Ribeiro O (1989) Opúsculos geográficos, II, O pensamento geográfico. Fundação Calouste Gulbenkian, Lisboa.

Ribeiro O (1985) Prefácio. In A ilha da Madeira até meados do século XX. Instituto de Cultura e Língua Portuguesa, Lisboa: 9-12.

Ribeiro O (1973) Um mestre da Geografia do nosso século, Emmanuel de Martonne. Finisterra Revista Portuguesa de Geografia, VIII(16): 163-263.

Ribeiro O (1971) Hermann Lautensach (1866-1971). Finisterra - Revista Portuguesa de Geografia, VI(12): 161-163.

Ribeiro O (1970) Variações sobre temas de ciência. Livraria Sá da Costa Editora, Lisboa: 241-250.

Ribeiro O (1955) Portugal, in Geografia de España y Portugal. Vol. V., Montaner y Simón, Barcelona.

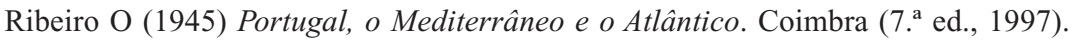

Ribeiro O, Lautensach H, Daveau S (1987-1991) Geografia de Portugal. 4 Vol., Edições João Sá da Costa, Lisboa. 